\title{
Los [dos] cartuchos de Nellie Gampobello
}

\section{Two Rounds of Cartucho by Nellie Campobello}

\author{
María José Ramírez \\ Universidad Nacional Autónoma de México \\ Instituto de Investigaciones Bibliográficas, México \\ machequina@gmail.com
}

\section{ResuMEN}

En 1931, Nellie Campobello publicó Cartucho. Nueve años más tarde, en 1940, apareció una segunda edición, de la cual se ha hablado poco. Salvo porque se la menciona para decir que fue bajo la influencia del autor de El águila y la serpiente que Campobello la modificó, la edición de 1940 quedó más o menos borrada por la tercera edición (1960), así como quedaron las características propias de una edición y otra. En este trabajo se hace un recorrido por algunos de los rasgos que distinguen ambas ediciones, con el afán de mostrar aquello que ya se encontraba en la primera edición y aquello que su autora agregó o potenció posteriormente. También se expone el contexto en el que surgió la segunda edición (el interés de Campobello por la historia, su relación con Austreberta Rentería, la publicación de su libro Las manos de mamá) y se cuestionan los motivos de la autora para plantear Cartucho (1940) como un conjunto de "cuentos verdaderos", en oposición a la "leyenda" revolucionaria fijada en la historia oficial. En el análisis realizado se observa la expansión de algunas de las estrategias literarias propias de la primera edición (la multiplicidad de voces testimoniales y la aportación particular de las mujeres como testigos de los hechos) y la permanencia de otras tal y como aparecieron en 1931 (la voz narrativa infantil, las imágenes poéticas asociadas a la guerra y a la infantilización de los hombres que pelearon en la Revolución). La premisa de este artículo es que ambas ediciones desafian los conceptos de verdad, historia y ficción, tal como los solemos concebir tradicionalmente, pero en 1940, Campobello expandió algunas de las estrategias literarias que utilizó en 1931 en función del énfasis que quiso poner en los testimonios de una multitud de mujeres y hombres que vivieron la guerra civil en el Norte y a quienes - consideraba la autora-, en el proceso de oficialización e institucionalización de la Revolución mexicana, se les había negado la verdad de su propia historia.

\section{Palabras Clave}

Nellie Campobello, Cartucho, crítica textual, Revolución mexicana, Literatura de la Revolución mexicana. 


\section{Abstract}

In 1931, Nellie Campobello published Cartucho. Nine years later, in 1940, a second edition appeared, about which not much has been said. With the exception that it is usually mentioned to assert that Campobello modified it under the influence of the author of The Eagle and the serpent, the 1940 edition was left somewhat erased by the third edition (1960), in the same way that each edition's corresponding characteristics were also erased. This piece reviews some of the features that characterize both editions, with the intention of showing what was already present in the first edition, and what the author added or enhanced afterward. It also presents the context in which the second edition emerged (Campobello's interest in history, her relationship with Austreberta Rentería, the publication of her book Las manos de mamá), and it questions the author's motives to propose Cartucho (1940) as a set of "true tales" in opposition to the revolutionary "legend" stated in official history. In the conducted analysis, we can appreciate the expansion of some of the literary strategies present in the first edition (the multiplicity of testimonial voices and the contribution of women as witnesses to the facts) and the permanence of others that appeared in 1931 (the infantile narrative voice, the poetic images associated to the war and to the infantilization of the men that fought in the Mexican Revolution). The premise in this article is that both editions defy the concepts of truth, history, and fiction, in the way we usually conceive them, but that in 1940, Campobello expanded some of the literary strategies that she used in 1931 as a function of the emphasis that she put in the testimonials of a multitude of women and men that lived the civil war in the North and to whom, in the process of officialization and institutionalization of the Mexican Revolution, the truth of their own history had been denied, according to the author.

\section{KEYWORDS}

Nellie Campobello, Cartucho, textual criticism, Mexican Revolution, Mexican Revolution Literature.

RECEPCIÓN: 14/01/2021

ACEPTACIÓN: 27/03/2021

¿[...] la guerra de Troya ocurrió alguna vez?

Blas Matamoro

G n 2005 leí por primera vez Cartucho de Nellie Campobello. Fue como ver una Apelícula que nadie podría borrarme de los ojos. Tenía tan clavada en la cabeza la sensación de haber visto una obra cinematográfica (más que la de haber leído un libro) que el texto titulado "Tragedia de Martín" lo escuchaba como si se tratara del corrido con el que debían aparecer en mi imaginación los créditos al finalizar la función. 


\section{Los [dos] cartuchos de Nellie Campobello}

Le creí todo a Campobello. Hasta que se llamaba Nellie y que se apellidaba Campobello. Luego vinieron no las dudas, sino la curiosidad, el chisme infatigable de los estudiantes de Letras y de los académicos. ¿Quién fue Nellie Campobello? ¿Quién publicó sus libros, quién los editó? ¿Sí era una niña cuando ocurrió la guerra o no? ¿Cómo murió? ¿Por qué?

La literatura es, ante todo, deseo, placer. Los humanos nos recreamos en el arte, es nuestra forma de desplegar la inteligencia por el puro gozo del juego. Después queremos significar ese juego, acomodarlo, utilizarlo. Dice Blas Matamoro, en un hermoso resumen de nuestra relación (occidental) con la verosimilitud, que para Platón los filósofos son los encargados de controlar el "seductor disparate" de los poetas, ese placer (Matamoro, 1987: 83). Los filósofos como policías. Ahora sabemos que la vigilancia sobre el deseo (¿descontrolado?) la ejercen los filósofos, la Santa Inquisición, el editor, el lector y hasta el propio autor. Quizás con mejores intenciones que un censor, la academia quiere también significar los juegos, acomodarlos, utilizarlos. ¿Qué es Cartucho? ¿Es una novela? ¿Son cuentos, son relatos, son estampas? ¿Son verdad? ¿Sucedieron los hechos narrados por su autora? ¿Por qué modificó Campobello el texto de 1931 a 1940? ¿Nos está mintiendo, sí o no?

A través de la literatura, se posibilita el acceso a ciertas verdades mediante la ficción, en ese sentido, la literatura miente. El arte miente. La memoria miente. Porque si la literatura no mintiera, si quisieran los poetas contarnos la verdad cuantitativa y nada más, intentarían hacer ciencia, pero la literatura nos aproxima a la verdad de otro modo, de un modo más cercano a la memoria. Si quisiéramos recordar todo tal cual es y venir a describir en detalle lo que pasó, tendríamos todos que ser Funes y viviríamos atormentados por la imposibilidad del olvido. La memoria y la literatura mienten en tanto que, en ellas, las personas crean estructuras propias para emitir un mensaje plagado de olvidos, de omisiones, de intuición, y que no se agota, pues es más grande que la estructura ficcional que lo soporta.

Nellie Campobello nos regala balas, amor por los muertos. En Cartucho no vamos a encontrar las explicaciones eruditas (o poco rigurosas o inconclusas) acerca de lo que significó la guerra civil que vivió México en las primeras décadas del siglo xx. No vamos a encontrar un listado exhaustivo de los daños sufridos ni de los nombres de los caídos o de los que pasaron a la posteridad como héroes triunfantes. Lo que hay son restos de ropa, tierra, sangre, últimos gestos, palabras finales, imágenes reconstruidas desde el anhelo de las mujeres, las madres, las vecinas, algunos conocidos. La sola dedicatoria de la edición de 1940 es una bala: "A mamá,/ que me regaló cuentos verdaderos en/ un país donde se fabrican leyendas y donde la/ gente vive adormecida de dolor oyéndolas". Nellie Campobello nos miente, recurre a una ficción para transmitir con vehemencia la verdad de las experiencias vividas en la guerra civil. Sus relatos son verdaderos. Su verdad se opone a las leyendas fabricadas, a la "historia oficial". En 1940 Campobello 
nos entregó las reglas del juego de una obra que se imprimió por primera vez en 1931, y con la que la autora desafia a la par los conceptos de literatura e historia.

\section{Los nombres de Nellie}

En El Universal Ilustrado del 13 de junio de 1929, cuando Campobello publicó su primer libro, Francisca, Yo!, Carlos Noriega Hope se refirió a Francisca como "el seudo que oculta a la autora" (Noriega citado en Vargas y García, 2013: 181), seguramente, sin saber que, en el acta parroquial de Villa Ocampo, Durango, Rafaela Luna registró a la misma autora como su hija natural con el nombre de María Francisca Luna, el 7 de noviembre de 1900.

Xica, le decían de niña; Zobeida, la adivinadora de Egipto, la llamaban sus clientes en un hotel en el que leía la suerte en Ciudad Juárez, en 1919; Nelly, Nelli o Nellie Campbell, para quienes la conocieron a partir de la década de los veinte en la Ciudad de México (véase Vargas y García, 2013).

El primer poema de su primer libro es una invitación a destruirlo todo: "Vamos al campo/ hermana": "A tirar piedras/ a los pájaros", "a pelear con los/ árboles y vencerlos", "A matar las mariposas/ y cortar todas las flores" (Campobello, 1929: s. p.). Cada poema parece una declaración de principios. Nellie Campobello vino de allá, de los cerros (su origen), a contarnos de la guerra, y quiso hacerlo con todo el ímpetu de su carácter arrollador y valiente.

Después de publicar sus primeros poemas (a través de Gerardo Murrillo, padrino de la edición), se fue a Cuba con su hermana Gloria (que también se había llamado Soledad). Iban rumbo a la Feria de Sevilla. Nunca llegaron, se quedaron en La Habana. Su pasaporte dice que nació en 1910, como la Revolución mexicana.

Las hermanas Campbell eran bailarinas. Del Norte, del frío, de la orfandad, de la carencia. De 1921 a 1929, las hermanas salieron adelante. No eran nadie para la Ciudad de México. Sus nombres los llevaba el río Florido, allá en Durango. Se bautizaron a sí mismas. "Yo soy Nellie", "Yo soy Gloria", ni Francisca ni Soledad. En Cuba hispanizaron el Campbell, así como sus danzas. El ballet clásico pasó a ser mexicano, y el apellido: Campobello.

La escritora regresó de la isla con dos cosas: un nombre nuevo y una libreta verde con el borrador de los relatos que reuniría Cartucho, su segundo libro.

\section{De 1931 a 1940}

\section{I}

La segunda obra de Nellie Campobello es también el trabajo por el que más se le conoce. Suele leerse la última edición publicada en vida de la autora, aquella que 


\section{Los [dos] cartuchos de Nellie Campobello}

se incluyó en Mis libros (1960) y que editó Martín Luis Guzmán, quien publicó, asimismo, la segunda edición (1940). Se ha hablado poco de la edición de 1940 y de los cambios que realizó la escritora de la primera versión a la segunda. Salvo porque se la menciona para decir que fue bajo la influencia del autor de El águila y la serpiente que Campobello la modificó, la edición de 1940 quedó más o menos borrada por la edición de 1960, así como quedaron las características propias de una edición y otra.

En su paso por La Habana, Campobello conoció a algunos escritores, entre quienes se encontraba el poeta estridentista Germán List Arzubide. A principios de 1931, en la Ciudad de México, la bailarina se reencontró casualmente con él, y el 13 de octubre, de ese mismo año, Cartucho salió de la imprenta. List Arzubide se encargó de la edición e inauguró con los relatos revolucionarios de Campobello el sello Ediciones Integrales. En el texto "Inicial", eliminado en 1940, aparecen Nellie y Gloria en la capital de Cuba narradas por las mismas balas que narran a los muertos en las páginas subsecuentes: "Gloriecita, mi hermana, se puso el vestido blanco de olanes [sic], era en la tarde, mi hermana se volvió muñeca 1930 para un anochecer con focos grandes en calles asfaltadas. Este retrato tiene retoque 1930 y está hecho con la cámara de un espejo de bolso", "nos llevó al Miami, consultamos el menú, para terminar con una sonrisa de tres pisos, en canapé de cabiar [sic]" (Campobello, 1931: I y II). Campobello traduce las ráfagas de la realidad en fotografías concisas.

En una entrevista realizada por Blanca Rodríguez en julio de 1994, List Arzubide dijo respecto a su trabajo como editor de Cartucho: "No le agregué ni le recorté nada, salió tal cual, lo único que hice fue agrupárselos por tema” (Rodríguez, 1998: 157).

La edición de 1931 está conformada por 33 relatos (además del ya mencionado "Inicial"). En 11 de los textos encontramos la voz de una narradora niña que expresa fascinación por los combates y por los muertos; la forma en la que este personaje describe lo que sucede a su alrededor, sin pudor ni temor, hace de ella una voz singular y novedosa, única en la literatura acerca de la Revolución mexicana. Quizás éste ha sido el rasgo más aclamado de Cartucho.

Para saber cómo rebotó de la montaña al llano y dominó el desierto el paso de los HOMBRES DEL NORTE, habrá que venir aquí siempre, donde una niña, que ha visto a esos hombres quebrarse entre sus manos indolentes de inocencia, jugaba con la risa crepitante de las ametralladoras. nellie campobello [sic] saca de su recuerdo el primer muñeco desquebrajado por las balas y lo extiende sobre la calentura de CUBA; y mientras danza, tiene entre sus manos la cabeza del último Bautista, profeta de discursos de incendio: Pancho Villa (Arzubide en Campobello, 1931: s. p.). ${ }^{1}$

${ }^{1}$ Así dice el texto sin firma que antecede al "Inicial" y que muy probablemente fue escrito por List Arzubide. 
La propia Campobello se presentó como la niña que narra, desdoblándose Francisca en el personaje Nellie, y Nellie en el personaje infantil que atestiguó la guerra; "A los cuatro años se me notaba, impresa en el rostro, la tragedia de la Revolución", le dijo a Irene Matthews en 1981 (Matthews, 1997: 35). Ahora sabemos que los hechos narrados en los relatos transcurrieron durante la adolescencia de Campobello. Con ello no se desacredita la voz infantil, sino que se le reconoce como un recurso literario poderoso y genial para contar verdades.

Una muestra de la eficacia de esta voz para describir los sucesos trágicos de la Revolución desde un punto de vista absolutamente original son los siguientes extractos del relato "Cartucho": "Cartucho no dijo su nombre. No sabía coser ni pegar botones. Un día llevaron sus camisas para la casa. Cartucho fue a dar las gracias. 'El dinero hace a veces que las gentes no se rían', dije yo jugando debajo de una mesa. [...] Cayó simpático por cartucho" (Campobello, 1931: 17). Desde ese lugar, bajo un mueble, la voz narrativa se adueña de una visión en la que un hombre adulto (que no se presenta y no sabe remendar sus camisas) se transfigura en algo pequeño (como ella), una bala. Cartucho es un personaje masculino que llora cuando canta (pues lleva la pena de un desamor), que monta a caballo y juega con Gloriecita (la hermana de la narradora que es una bebé), y hasta se la lleva en brazos mientras tira balazos. Después de su muerte, José Ruiz, uno de sus compañeros, dice: "Cartucho ya encontró lo que quería", y después: "El amor lo hizo un cartucho. ¿Nosotros?... Cartuchos" (Campobello, 1931: 18 y 19). Campobello nos presenta a los hombres de la Revolución como algo que se opone al estereotipo del héroe masculino tradicional (fuerte, grande, invencible, trascendental, con un nombre propio que pasará a la historia), y basta con la mirada atenta de una niña para describirlos: "José era filósofo. Tenía crenchas doradas untadas de cebo y lacias de frío. Los ojos exactos de un perro amarillo" (Campobello, 1931: 18).

Pero en Cartucho de 1931 hay también otras voces. Por ejemplo, en el relato "El Kirilí", la voz que cuenta la historia de dicho personaje es la de una narradora omnisciente en tercera persona; gracias a su conocimiento, sabemos lo que se decía de él: "Cantaba mucho porque se decía: 'Kirilí, qué buena voz tienes"” (Campobello, 1931: 23); lo que el propio Kirilí expresaba: "decía que él había matado puros Generales, Coroneles y Mayores" (Campobello, 1931: 23); lo que decían sus compañeros (Gándara y el Peet): "le decían que no fuera tan embustero" (Campobello, 1931: 23 y 24); aquello que le advirtieron antes de que se metiera a bañar a un río: "alguien le dijo que venía el enemigo" (Campobello, 1931: 24); y lo que pasó con su enamorada y con su madre después de su muerte: "Chagüita se vistió de luto, y poco tiempo después se hizo mujer de la calle. Doña Magdalena que ya no tiene dientes y se pone anteojos para leer, lo llora todos los días allá en Chihuahua" (Campobello, 1931: 24). 


\section{Los [dos] cartuchos de Nellie Campobello}

En donde no puede haber una niña, hay una voz omnisciente; lo que no puede saber la niña, lo sabe dicha voz, transmisoras ambas de múltiples testimonios.

En 1934, Campobello emprendió una batalla pública y legal en favor de Austreberta Rentería, viuda de Francisco Villa, lo cual la llevó a publicar, a lo largo de esa década, numerosos artículos periodísticos al respecto, así como otros dedicados a exaltar la figura del Centauro del Norte (algunos de estos textos los incluyó posteriormente en su libro Apuntes sobre la vida militar de Francisco Villa). Nellie quería rescatar el nombre de Villa, salvarlo de la ignominia. Gracias a la cercanía con la que fuera la esposa del líder villista, la bailarina tuvo en sus manos un archivo que le permitió escribir su cuarto libro (los ya mencionados Apuntes) y también firmar un contrato con Rentería y con Martín Luis Guzmán, pues el archivo también fue utilizado por éste para elaborar sus Memorias de Pancho Villa; ambos libros se publicaron en 1940, en la editorial EDIAPSA, fundada por Guzmán y Rafael Giménez Siles (en 1939). Ese mismo año, dicho sello sacó a la luz la segunda edición de Cartucho. Pero antes de ello, en diciembre de 1937, Nellie Campobello publicó Las manos de mamá en la Editorial Juventudes de Izquierda, editorial creada por el escritor José Muñoz Cota. Nellie quería regresar a Francisca (sin nombrarla) a través del recuerdo de su madre, Rafaela. Para ello, había que volver sobre la historia. Campobello se convirtió en acuciosa investigadora de una guerra de revolución que hacía no mucho había concluido y cuyo proceso de institucionalización se encontraba en plena marcha. Su trabajo como bailarina la mantuvo cerca de los nuevos esquemas políticos, bajo los cuales se organizó la cultura nacionalista y con los que no siempre estuvo de acuerdo. Cuando escribió el prólogo a Mis libros, en 1960, recordó las contradicciones de la vida nacional que la llevaron a buscar su propia verdad a través de la escritura:

Amar al pueblo no es sólo gritar con él en fiestas patrias, ni hacer gala de hombría besando una calavera de azúcar, ni rayar un caballo, ni deglutir de un sorbo media botella de tequila. Amar a nuestro pueblo es enseñarle el abecedario, orientarlo hacia las cosas bellas, por ejemplo, hacia el respeto a la vida, a su propia vida y, claro está, a la vida de los demás: enseñarle cuáles son sus derechos y cómo conquistar estos derechos; en fin, enseñarle con la verdad, con el ejemplo; ejemplo que nos han legado los grandes mexicanos, esos ilustres mexicanos a los cuales no se les hace justicia. ¿Será porque no hemos tenido tiempo? ¿Porque los ignoramos? Se podría decir: ¿Por qué no sabemos? (Campobello, 1960: 29).

Y continúa: "En medio de esos pensamientos, nacidos del ambiente que me rodeaba, traté de escapar, refugiándome, cosa natural en mí, en la falda de mi madre. Fuime, pues, directamente, a ese oasis, a mi oasis, y [...] me puse a escribir" (Campobello, 1960: 29).

La verdadera historia no la contaba el gobierno (de Carranza a Calles, como lo dice explícitamente en el mismo prólogo), sino las voces de su pasado, empezando por su madre. Pensar Las manos de mamá, y aquello que motivó a su autora a escribirla, 
como una parada antes de la segunda edición de Cartucho, tal vez pueda ayudarnos a ver con nuevos ojos los cambios que realizó Campobello de una edición a otra.

\section{II}

En 2009, José Roberto Gallegos Téllez publicó 18 cartas encontradas en el archivo del escritor Martín Luis Guzmán (bajo resguardo del Archivo Histórico de la Universidad Nacional Autónoma de México) que dan cuenta de la relación que mantuvo con Campobello. En su artículo "Correspondencia Martín Luis Guzmán-Nellie Campobello", Gallegos presenta el conjunto de cartas dividido en tres grupo; el primero se compone de correspondencia fechada a finales de los años 30 y de temática personal; estas cartas las encontró el investigador "revueltas con materiales de trabajo de las Memorias de Pancho Villa" (Gallegos, 2009: 61). ${ }^{2}$ El segundo grupo se ubicaba en el expediente del escritor titulado "Villa Ocampo", dentro de la correspondencia firmada por Guzmán durante su trabajo como director de la revista Tiempo. Y, finalmente, el tercer grupo está conformado, en su mayoría, por los recibos de pago que realizó Guzmán tanto a Austreberta Rentería como a Campobello por las regalías de las Memorias (los pagos se extienden hasta 1981).

El descubrimiento de estos documentos ha resultado fundamental para entender mejor la historia editorial de la obra de Campobello. Gracias a cuatro de las cartas que se encuentran en el primer grupo, sabemos que la escritora compartió con Guzmán el manuscrito de Las manos de mamá, que le pidió que lo leyera (e incluso que lo corrigiera) y que, hasta donde este intercambio epistolar nos permite dilucidar, él no cumplió con dicha petición como veremos más adelante.

La primera carta que presenta Gallegos no tiene fecha ni firma, muy probablemente sea el borrador de una carta enviada de Guzmán a Campobello. La misiva fue escrita a mano por el autor de $A$ orillas del Hudson, con lápiz, "con su típica y característica letra" (Gallegos, 2009: 63). Se trata, sin lugar a ninguna duda, de un mensaje entre amantes, amantes con una historia y en conflicto (al momento). ${ }^{3}$ La carta fecha-

\footnotetext{
${ }^{2}$ Las cartas reproducidas por Gallegos Téllez que cito en este artículo provienen de AHUNAM, MLG, sección Personal, subsección Correspondencia, serie Correspondencia Literaria, caja 39, expediente 24, 18 fojas. Junto con las cartas, Gallegos encontró, en el archivo de Guzmán, copia de todos los artículos publicados por Campobello de temática villista.

3 "La señorita avergonzada de que la acusen de ser mi amante no me atrae, ni me hace falta, ni me interesa. Porque una devoción como la mía, en cualquier situación social que la rodee, no espera avergonzar a nadie que sepa merecerla, corresponderla y ostentarla. Se avergonzará de mí quien oyéndose llamar mi amante no sepa con toda la luz de su inteligencia y en todo el impulso de su corazón, y que en todo eso no responda que no es mi amante sino mi mujer, Nellie" (Gallegos, 2009: 66).
} 


\section{Los [dos] cartuchos de Nellie Campobello}

da de mayor antigüedad (8 de septiembre de 1936) la colocó Gallegos hasta el final de su artículo. En ella, Guzmán le escribe a Campobello desde un barco, llamándola cordialmente "Mi querida y buena amiga" (Gallegos, 2009: 74). El tono del mensaje, aunque amable, es distante; no está de más señalar que la mayor parte de sus líneas las dedica Guzmán a halagar Cartucho, lectura que lo acompañó "en el trayecto de México a Laredo":

Es usted una escritora dotada de muy grandes cualidades. Cuáles sean éstas no se lo digo en obediencia a mi doctrina sobre estas materias. Ya sabe usted que, a mi juicio, no es bueno hacer a los autores jóvenes la disección de sus obras, porque con ello lo más probable es que se les aparte de su verdadero camino, que es el que la intuición va abriendo poco a poco (en Gallegos, 2009: 75).

Para la primavera del año siguiente, la relación entre los escritores se había transformado. Mayo 27 de 1937, Campobello a Guzmán: "El segundo favor que le imploro es que no se olvide de ir a cumplir con lo que me prometió (lo que me falta corregir de las manos de mamá)" (en Gallegos, 2009: 66); mayo 31, Campobello divide su carta en falsas secciones de periódico, y en la sección "Encargos" se lee: "La (2) Mona. El (3) Coral. El libro de mamá (1)" (en Gallegos, 2009: 67); 2 de junio: "Espero cumpla mis encargos, el libro tiene las palabras de mamá" (en Gallegos, 2009: 68); 5 de junio: "No estoy nada contenta con su tatacitabire acerca de las manos de mamá me da mucho sentimiento que no lo haya hecho" (en Gallegos, 2009: 68). ${ }^{6}$ Si de esta fecha a diciembre (cuando se imprimió el libro) Guzmán leyó y corrigió dicho manuscrito, no contamos con ningún testimonio de ello. Sabemos cuál fue la postura que tomó él frente a la "disección" de la primera edición de Cartucho y sabemos cuál fue su postura (al menos inicial) frente a la corrección del segundo libro de relatos revolucionarios de Campobello.

La correspondencia encontrada por Gallegos da cuenta de una relación que se extendió a lo largo de varias décadas. Indagar el grado de intimidad que supuso dicha relación no es de nuestra incumbencia. Lo indiscutible y útil para mí son ciertas palabras escritas en las cartas que dejan en paz falsas suposiciones acerca de la historia editorial de los libros de Nellie Campobello. Es posible que Guzmán no leyera Las

\footnotetext{
${ }^{4}$ Por esta y otras menciones, se entiende que la Mona y el Coral son dos caballos que ambos montan en Chapultepec y a los que les tienen mucho afecto.

${ }^{5}$ El subrayado lo transcribe Gallegos del original. Esta carta aparece en el artículo con fecha (entre corchetes) del 2 de julio de 1937, el mes parece tener una errata y debe ser más bien junio, pues la carta siguiente tiene fecha del 5 de junio del mismo año.

${ }^{6}$ Guzmán la llamaba cariñosamente "tatacita", que deriva del tarahumara "tata", que quiere decir "padre"; por las cartas se infiere el uso lúdico y amoroso de expresiones en la lengua de los rarámuris.
} 
manos de mamá antes de su publicación y resulta un hecho que valoraba y respetaba el trabajo de la escritora.

En una de las cartas de 1937 que recuperó Gallegos, Campobello dice: "Pedrito Davila del Edo Mayor de [Francisco Villa] y paisano mio de Villa Ocampo me dá datos maravillosos que ya le enseñaré á Ud. Para que vea que su historiadora es muy escrupulosa en eso de los datos" (en Gallegos, 2009: 68). ${ }^{7}$ Campobello indagó para Guzmán y también para sí misma.

\section{III}

Con Las manos de mamá, Campobello se propuso componer un homenaje a su madre, Rafaela, quien murió en 1922; los primeros textos dan cuenta de ello en un tono solemne y lírico; pero muy pronto comienzan a aparecer los rifles, los soldados, la guerra, la voz narrativa que recurre a su posición infantil y a la infantilización de los machos revolucionarios. El recuerdo de su mamá está atado a esa experiencia de la Revolución, y su testimonio se entrelaza con otros testimonios, incluido el de aquella niña que aparece también en Cartucho. En el relato "Ella y la máquina", dice:

La máquina, muñeca tosca, se quedaba abandonada; las bastillas arrugadas estrangulaban a veces la rueda, brillante como anillo de estrellas. La aguja mordía despiadada las puntas de aquellos pedazos de tela. ¿Qué era el pobre sonido de aquella máquina junto al murmullo del cañón? Nada, inútil moverla. Me daba risa oírla junto al canto del cañón. ¡Pobrecita máquina que nos regalaba bastillas mientras el cañón nos regalaba muertos! Nuestras calles quedaban [s]embradas con aquellos cuerpos fuertes y jóvenes, tirados en el suelo sobre las bastillas que sus mamás les habían puesto en sus camisas. ¿Para qué les servían? ¿Para qué se las pusieron?

“CGuántos kilos de carne harían en total? ¿Cuántos ojos y pensamientos? Y todo estaba muerto en aquellos hombres". Esto decía mi mente de niña precoz. Si los hombres supieran que inspiran lástima en su última posición, no se dejarían matar. “¿Cuántas lenguas? ¿Cuántos ojos?” (Campobello, 1937: 65 y 66).

Y más adelante: "Hombres fuertes tirados allí como regalo de mis ojos, apretado entre los dedos las bastillas que sus mamás les pusieron en la orilla de sus ropas deslavadas" (Campobello, 1937: 65 y 66). También en "Las barajas de Jacinto" es ese narrador el que no sólo formula imágenes poéticas con múltiples repercusiones textuales, sino que termina sus relatos con unas líneas contundentes, las cuales van cerrando el círculo de referencias que compone la imagen total de ambos textos: "Jacinto Hernández, con su pantalón de charro negro ajustado a sus piernas rectas y fuertes, se quedó abierto de brazos en el puente rojo un día que le pegaron el quién

${ }^{7}$ Se conserva la ortografía original de la carta. 


\section{Los [dos] cartuchos de Nellie Campobello}

vive, y que caminó testereando como niño que da los primeros pasos" (Campobello, 1937: 70).

Tres años y medio después de publicar la primera edición de Las manos de mamá, la segunda edición de Cartucho salió de la imprenta, el 16 de agosto de 1940. Pero, ¿qué cambió? ¿Qué de nuevo, qué de diferente era respecto al Cartucho de 1931? Las variantes son muchas, pero la forma en la que se han interpretado desde que la obra de Nellie Campobello comenzó a estudiarse también ha cambiado a la luz de nueva información sobre su vida y sobre la historia de sus libros. En 2018 concluí una edición crítica en la que tomé la decisión de fijar la edición de 1931 para, a partir de ella, observar las variantes de las ediciones subsecuentes. Esto es lo que encontré.

En 1940, en lugar de "Inicial", Campobello escribió el epígrafe-balazo dedicado a su madre: los cuentos verdaderos. Ya no se trata de 33 relatos/estampas/instantáneas, sino de 56 (el texto "Villa" ya no está). La autora conservó la agrupación original propuesta por List Arzubide, aunque movió algunos textos de lugar. En varios relatos, la autora modificó el lenguaje, como en "Zafiro y Zequiel", en el cual cambió la palabra "voltié" por "voltee", haciendo distancia respecto al registro popular del habla. Aunque en "Mugre", "voltió" se conservó, y Campobello la modificó hasta la edición de 1960, lo cual podría interpretarse como que no tenía, en 1940, una voluntad por corregir de forma meticulosa este tipo de rasgos originarios de la primera versión. Si se revisan concienzudamente las variantes en los distintos testimonios, en realidad, los cambios efectuados parecen responder a la voluntad (como es la voluntad de cualquier escritor) de mejorar la obra. Quien escribe, reescribe siempre. El texto definitivo no existe. De ahí que varios de los cambios realizados por Campobello sean inserciones (o extracciones) de signos de puntuación. Es decir, vistos como casos particulares, las ocasiones en que decidió cambiar una coma por un punto o la estructura de una oración podríamos darnos a la tarea de analizarlas y observar sus implicaciones a nivel sintáctico, y de ello derivar la interpretación de su voluntad, de lo que quiso lograr mediante esa ligera variación. Sin embargo, cuando se examinan con cierta distancia las variantes, no como casos aislados, sino tomando en cuenta la frecuencia con que se llevó a cabo tal o cual operación (modificación), como sucede al realizar una edición crítica, entonces podemos ver el carácter general del nuevo filtro que supuso volver al texto e imprimirlo bajo una nueva serie de criterios.

En su libro Nellie Campobello: eros y violencia, Blanca Rodríguez señala el uso de la elipsis y la fragmentación como rasgos distintivos del estilo de Cartucho en 1931 (Rodríguez, 1998: 166). Pero se trata de rasgos distintivos del estilo de Campobello más allá de Cartucho (la escritura como bala, como fotografia), pues éstos se repiten, aunque de forma moderada, en otros de sus textos. Recordemos las palabras con las que describe su llegada al puerto de Veracruz en el prólogo a Mis libros: "Las calles reverberaban; antorchas de sol azotaban el rostro. Gritos, monedas, mugre, manos morenas, dientes 
blancos, aguas frescas, bocas anchas; olores, todos los olores de un puerto sucio. Sonrisas, piernas ligeras, ojos cansados, rítmicos pasos en interminables aceras" (Campobello, 1960: 19); o en el siguiente fragmento de Apuntes sobre la vida militar de Francisco Villa: "En la plaza principal, tres compañías de americanos acampadas. Y llegaba el día. Los soldados comían echados en las banquetas" (Campobello, 2007: 304); o en sus cartas a Guzmán: "Nada ha cambiado[,] todo sigue igual. Nuestra casa se llama el Castillo de la Sardina. Nuestro restaurante se nombra el cedazo./ Ayer bailamos alrededor de una fuente[,] eran las cinco y media" (en Gallegos, 2009: 69). Para sostener su argumento, Rodríguez usa, entre otros, el siguiente ejemplo:

"Bartolo". Se añadió una oración simple para suplir la elipsis "era", señalada entre corchetes:

Un día llegó una reina a casa de Anita; parecía pavo real, la cara muy bonita y los dedos llenos de piedras brillantes. [era] La hermana de Bartolo de Santiago.

Un día llegó una reina a casa de Anita; parecía pavo real, la cara muy bonita y los dedos llenos de piedras brillantes. [era] La hermana de Bartolo de Santiago, dijeron las voces (Rodríguez, 1998: 166). ${ }^{8}$

En realidad, la elipsis prevalece, pues, como se puede ver, se sigue omitiendo el verbo "era", pese a que se añadió un sujeto y "La hermana de Bartolo de Santiago" pasó a ser una oración subordinada sustantiva de objeto directo. En otro ejemplo, Rodríguez dice:

Aunque la elipsis es una característica del estilo de Campobello, la supresión del verbo "era" en este caso, rompe el ritmo de la primera versión, rigidizando la nueva entrada.

Ejemplo de "El general Rueda":

Era un hombre alto, tenía bigotes güeros, hablaba muy fuerte.

Hombre alto, tenía bigotes güeros, hablaba muy fuerte (Rodríguez, 1998: 164).

Las modificaciones de Campobello son inconstantes, es decir, a veces quita y otras añade, no sigue un criterio fijo. En lo que parecen haber sido constantes las variantes es en la aplicación de las reglas de ortografía y en la unificación del uso de los signos de puntuación.

Blanca Rodríguez asegura también que Campobello eliminó la subjetividad del narrador en la segunda edición. Sin embargo, ya sabemos que en Cartucho, desde 1931, hablan muchas voces. La crítica que se desprende suele reiterar las característi-

\footnotetext{
${ }^{8}$ En los ejemplos de Rodríguez, la primera versión siempre es la de 1931 y la segunda, la de 1940. Tanto los corchetes como las cursivas son de la autora en todos los fragmentos aquí citados.
} 


\section{Los [dos] cartuchos de Nellie Campobello}

cas de un narrador infantilizado que se asume siempre femenino, pero ya vimos que no es la única voz que habla en el texto. Por encima de ésta, hay una voz narrativa que no podríamos catalogar como infantil, sino, a grandes rasgos, como la de una mujer adulta que recuerda o que recrea, en primera o tercera persona y en tiempo pretérito, algún suceso. Esas son las voces que se pueden encontrar en Cartucho de 1931. El narrador infantil aparece con toda claridad tan sólo en 19 de los 56 relatos de 1940; mientras que la voz narrativa adulta es la que en 41 relatos hila su voz a la de otros; en algunos casos, la encontramos ligada a la de la niña, en otros, además de ésta, aparece la voz de la mamá o la de algún otro personaje, siempre como un espectador o un transmisor oral de una historia local, cuyo testimonio es expuesto por el narrador como tal: "Dice Chonita, contenta de recordarlo", "Así fraseaba un poeta del pueblo que me narró espontáneamente la muerte del general Martín López", "Isaías Álvarez dice", "Pepita Chacón, entre risas amables, recordó", "Severo me relata, entre risas, su tragedia", "Julio nos dijo - cuentan sus compañeros —" (véase Campobello, 1940), por poner algunos ejemplos. De esa narradora adulta que recuerda (desde 1931) provienen las imágenes poéticas de los relatos. La voz infantil predomina en la narración de tan sólo cinco relatos: "Cartucho" (renombrado "Él"), "Cuatro soldados sin 3030", "Zafiro y Zequiel”, "El muerto" y "Las tripas del general Sobarzo", y aunque en éstos encontramos imágenes poéticas de mucha fuerza, no podemos ligar a la niña al resto de las imágenes que colman el texto, sino a la voz de la mujer que, en el relato "Las rayadas", se asume como "Nellie". 9

Existen grandes diferencias entre una edición y otra. Me atrevo a decir que la voz de la niña no aparece en ninguno de los 24 relatos añadidos en 1940. En éstos no predomina tampoco la voz narrativa de la mujer adulta, sino el testimonio de los otros hilado o presentado a través de ésta, de tal manera que son las voces de una multiplicidad de testigos - que van desde un individuo habitante de Parral hasta la voz de la tradición popular y plural del corrido revolucionario - las que tienen la palabra, aunque hay claros destellos de una voz poética que correspondería a la de esa personalidad adulta que ya estaba presente en 1931. Ejemplo de ello es "El milagro de Julio", relato añadido en 1940, en el que la voz narrativa evoca lo infantil para hablar de la guerra:

El combate estaba fuerte, tuvieron que ir agazapándose en las esquinas, parecían papeles que se llevaba el viento. Al volver a la iglesia todos entraron corriendo, Julio fue el último. Apenas pudo llegar; ya iba herido. Se recargó en la puerta por dentro. Cuando lo buscaron, el milagro se había hecho. Julio estaba quemado. Su cuerpo se volvió chiquito. Ahora era ya otra vez un niño (Campobello, 1940: 154).

\footnotetext{
${ }^{9}$ Dice el relato: "Pues verás, Nellie, cómo por causa del general Villa me convertí en panadero" (Campobello, 1940: 157).
} 
Y termina diciendo: "Lo enterraron en una caja chiquita. Los hombres que lo llevaron al camposanto lo iban meciendo al ritmo de sus pasos" (Campobello, 1940: 154).

En 1940, Campobello logró diversificar la voz narrativa, y sus motivos para hacerlo podrían ser dos: uno, otorgar un lugar preponderante a su madre, y a las mujeres en general, en la narración de la historia; y otro, su creciente interés por el trabajo historiográfico que, necesariamente (o al menos así parece haberlo concebido Campobello), debe estar apartado del quehacer literario y sus recursos y, por lo tanto, debe separarse de la afectividad expresada por la voz narrativa de la niña que ha hecho suyos a los muertos. La dedicatoria de 1940 revela la importancia de rescatar el papel de Rafaela Luna como testigo de la guerra, como informante de acontecimientos históricos, de verdades. En el relato "Los 30-30", la autora agregó, hacia el final de la narración, la oración: "Mamá presenció todo" (Campobello, 1940: 48). En el relato "Los hombres de Urbina", las modificaciones a la voz narrativa se realizaron en función de otorgarle mayor protagonismo a la madre. La voz infantil está, pero moderada por la de la narradora adulta que recuerda. En 1931, el texto comenzaba diciendo:

Un día, allá en la hacienda de Las Nieves, Estado de Durango, donde Urbina vivía, entraron a balazos muchos villistas; sorprendieron a la poca gente que acompañaba al general y mataron algunos. Lo contó Kirilí, el hijo de doña Magdalena, un muchacho que vivía con Urbina. Urbina estaba herido, lo llevaron prisionero. En la mitad del camino entre Parral y Villaocampo, al reflejo de unas grandes lumbraradas, lo fusilaron junto con otros; cuentan que aquello era tan oscuro que parecía una pesadilla. Villa había matado al compadre Urbina y lo dejó enterrado. (A Villa le sorprendió mucho la noticia, su compadrito había muerto en una balacera, parece que el general Fierro le contó que el general Urbina se estaba volteando al lado de Carranza, y realmente él había tenido que intervenir a balazos. Los norteños sabían que la muerte de Urbina se debió a una corazonada del Jefe de la División del Norte) (Campobello, 1931: 101).

Y en 1940:

Le contaron a mamá todo lo que había pasado. Ella no lo olvidaba. Aquellos hombres habían sido sus paisanos. Fue en Nieves - dijo mamá - allá en la hacienda de Urbina, entraron a balazos los villistas, Isidro estaba allí (el Kirilí), los sorprendieron. Ellos eran muy pocos y mataron a los más. A Urbina lo hirieron, luego se lo llevaron preso rumbo a Rosario, no llegaron; Urbina se perdió. La noche era tan oscura que parecía boca de lobo. Contaron que al general Villa le había sorprendido mucho la noticia de la muerte de su compadre Urbina, pero todos supieron que Fierro le dijo que Urbina se andaba volteando y que realmente él había tenido que intervenir a balazos. Mamá decía que todo se debió a una corazonada del Jefe de la División del Norte (Campobello, 1940: 83).

Esta hipótesis se confirma al comprobar que en 11 de los 24 relatos añadidos se menciona a la mamá de la voz narrativa como narradora en tercera persona o como 


\section{Los [dos] cartuchos de Nellie Campobello}

personaje que refiere la anécdota o que añade comentarios al respecto de ésta en primera persona. En otros cuatro, "Tomás Urbina", "Los oficiales de la Segunda del Rayo", "Abelardo Prieto" y "Las mujeres del Norte", se hace mención de otras mamás; el primero dice: "Su madre, doña Refugio, se desvelaba esperándolo" y "Había el antecedente de que doña Refugio, la mamá de Urbina, y el general Villa, se querían entrañablemente"; el segundo: "Mataron al Taralatas; pobrecita de su mamá"; el tercero: "Su madre lloraba triste/ con el corazón partido"; y el cuarto: "Madrecita - dijo Elías Acosta - horita vengo, cuide que no se me enfríe mi caldo", "Ya nos vamos, madrecita, porque vienen muchos changos", "Por allí se fueron', decía levantando su brazo prieto y calloso, Chonita, la madrecita de Elías Acosta y de tantos otros" y "los brazos de las madrecitas de ocasión señalan los lugares" (Campobello, 1940: 109, 179, 187 y 199, respectivamente). Además, este último relato, "Las mujeres del Norte", es muy importante, ya que no sólo funciona como homenaje a las madres que vieron a sus hijos morir en la guerra, sino que habla de una dinámica social en la que las mujeres permanecían y los hombres se iban, de manera que los miembros femeninos de la colectividad se volvían cronistas de guerra, pues atestiguaban el paso de los diferentes bandos y ejércitos revolucionarios mientras esperaban el regreso de los suyos. Seguramente, así esperó Rafaela a Felipe de Jesús, el padre de Campobello. No por nada la narración concluye diciendo: “'Pero ellos volverán en abril o en mayo!', dicen todavía las voces de aquellas buenas e ingenuas mujeres del Norte" (Campobello, 1940: 202). También, en el relato "Los oficiales de la Segunda del Rayo", la narradora habla de otras mujeres, de todas aquellas "muchachas de la Segunda del Rayo [que] se olvidaron de los oficiales, y dieron hijos a otros hombres" (Campobello, 1940: 183), pues sus galanes se fueron a pelear y no volvieron. Puedo decir que, pese a que siguen siendo los hombres los protagonistas de las batallas y de los fusilamientos, son las mujeres las que atesoran los relatos, las que transmiten de manera oral los hechos regionales, convertidos con el paso del tiempo en leyendas. Si en la versión de 1931 tanto la madre como la hija ya tenían un papel fundamental en el desarrollo de los acontecimentos, en 1940 se hace patente su rol activo en la transmisión de la historia. Es quizá por ello que eliminó el relato "Villa", pues aunque en él describía la cercanía de su madre con el Centauro, también lo presentaba rechazando prestar ayuda a una muchacha que venía con un "chiquito", llamándola "piedra suelta", como si, en los términos del General, sólo las "esposas legítimas" de sus hombres tuvieran derecho a ser ayudadas.

En resumen, Cartucho es, de 1931 a 1940, muchas voces, muchos cartuchos.

\section{La verdad y la Historia}

Una de tantas verdades es que, para 1915, cuando Nellie era todavía Francisca y los rifles atravesaban los muros de las casa en Hidalgo del Parral, la División del Norte 
vivía su (desesperada) disolución. Antes del verano, la guerra civil se había extendido por todo el país.

Del 6 de abril al 5 de mayo de 1915, en varias derrotas sucesivas que tuvieron como escenario la región del Bajío, la poderosa División del Norte fue aniquilada; el general Villa, con un pequeño ejército, se replegó en Chihuahua, donde la gente no quería aceptar la magnitud del desastre. La estrella del invencible general se venía abajo; sin embargo, la guerra no terminaba (Vargas y García, 2013: 112).

En su condición de derrotados, los villistas optaron por esconderse entre combate y combate, presentando una estrategia militar guerrillera que funcionó, en buena medida, gracias a la simpatía que los habitantes de la región les profesaban. Muy pronto, aquellas personas que habían declarado abiertamente su apoyo a Villa sufrieron las consecuencias, pues los carrancistas se encargaron de recordarles constantemente su traición, por medio de maltratos, robos y demás abusos. La familia de Campobello vivió en carne propia las represalias cuando un grupo de hombres entró a su casa para robarles, como lo cuenta en el relato "El general Rueda". Alfredo Quijano Rueda fue villista hasta la muerte de Tomás Urbina, en septiembre de 1915, cuando el Centauro del Norte, según palabras del historiador Pedro Salmerón, "ya estaba vencido, pero se negaba a aceptarlo" (Salmerón, 2015: 282).

En la segunda mitad de julio recibieron la orden de concentrarse en Torreón las fuerzas que iban abandonando diversas posiciones frente al avance carrancista. Al mismo tiempo, procedente de Monclova y su región, llegó a Ciudad Camargo la columna del general Rosalío Hernández. Sospechando cada vez más de la conducta de Urbina, Villa le entregó al rival regional del León de Durango [Urbina], el general Manuel Chao, el mando militar del sur de Chihuahua y el Norte de Durango, con sede en Parral, y le ordenó vigilar atentamente los movimientos de su compadre (Salmerón, 2015: 282).

Y más adelante, una vez asesinado Urbina por Rodolfo Fierro en Las Nieves:

La previsión de Villa sobre la mayor peligrosidad de Urbina se confirmó, pues aunque Rosalío Hernández ya no se presentó en Ciudad Camargo, a donde envió a sus tropas, y no tardó en someterse a los constitucionalistas, muchos de sus hombres permanecieron en las filas villistas. En cambio, poco después se conoció la deserción de los generales Alfredo Rueda Quijano y Donato López Payán, con mucha gente de Urbina; y en noviembre el general Petronilo Hernández no sólo gestionó que reconocieran al gobierno de don Venustiano esos dos generales, además de Santos Ortiz y Jacinto Hernández, sino que al frente de ellos participó en la invasión constitucionalista al estado de Chihuahua: fueron las fuerzas de don Petronilo, junto con contingentes de los inveterados enemigos del villismo Domingo Arrieta y Luis Herrera [hermano de Maclovio Herrera, villista hasta agosto de 1914], los que arrebataron Hidalgo del Parral a los villistas el 24 de noviembre (Salmerón, 2015: 288). 


\section{Los [dos] cartuchos de Nellie Campobello}

Este párrafo resulta relevante, pues no sólo menciona a Alfredo Rueda Quijano, sino también a otros villistas que se escindieron del movimiento cuando la derrota estaba cerca y Urbina fue ultimado, y cuyos nombres se mencionan en Cartucho, tales como el de Santos Ortiz, fusilado a manos de los propios villistas, según la edición de 1940. No es una casualidad que los dos relatos que más modificaciones sufrieron de 1931 a 1940 son los que hablan de la muerte de Tomás Urbina ("Los hombres de Urbina" y "La muerte de Tomás Urbina" /"Tomás Urbina"), pues el general encarnó una figura de muchísimo peso para los revolucionarios del Norte y, tanto su muerte como la forma en que ésta ocurrió, representó un golpe emocional para las personas que apoyaban a Villa. Urbina fue una de las principales e iniciales figuras destacadas del villismo duranguense, es decir, del más aguerrido de los villismos; por ello era respetado y admirado como jefe militar, así como por su participación, al lado de Calixto Contreras y de Orestes Pereyra, en la devolución de las tierras al pueblo, que los hacendados regionales se habían adueñado ilegalmente; desde 1912, Urbina, junto con los ya mencionados, fraguó dicha entrega a quienes les habían sido arrebatadas (véase Ávila y Salmerón, 2017: 212). En 1931, su funesta muerte fue narrada por Campobello en estos términos:

Un día, allá en la hacienda de Las Nieves, Estado de Durango, donde Urbina vivía, entraron a balazos muchos villistas; sorprendieron a la poca gente que acompañaba al general y mataron algunos. Lo contó Kirilí, el hijo de doña Magdalena, un muchacho que vivía con Urbina. Urbina estaba herido, lo llevaron prisionero. En la mitad del camino entre Parral y Villaocampo, al reflejo de unas grandes lumbraradas, lo fusilaron junto con otros; cuentan que aquello era tan oscuro que parecía una pesadilla. Villa había matado al compadre Urbina y lo dejó enterrado. (A Villa le sorprendió mucho la noticia, su compadrito había muerto en una balacera, parece que el general Fierro le contó que el general Urbina se estaba volteando al lado de Carranza, y realmente él había tenido que intervenir a balazos. Los Norteños sabían que la muerte de Urbina se debió a una corazonada del Jefe de la División del Norte) (Campobello, 1931: 101).

Según el testimonio de 1931, ¿quién asesinó a Urbina?, ¿Villa o Fierro? La forma confusa en la que Campobello describió el hecho refleja la sensación que debieron tener los Norteños conforme les fueron llegando los rumores acerca del fallecimiento de su jefe. El relato continúa:

Llegaron las tropas del difunto Urbina a Parral. Aquello era espantoso. Andaban destanteados; chorreras de hombres por las calles, con las caras desencajadas de coraje; algunos grupos eran altos, daba dolor verlos, aquellos miles de huérfanos todavía tenían la esperanza de que su jefe viviera. Lo buscaban, lo pedían a las gentes, a los postes, a las banquetas (Campobello, 1940: 101-102).

Es probable que, para 1940, Campobello tuviera más información acerca de aquella noche del 4 de septiembre de 1915 y es posible, también, que intencional- 
mente buscara aclarar el hecho a costa de sacrificar el acierto literario de expresar el sentir de los villistas en una redacción incoherente o desordenada; de ahí que ese primer párrafo se volvió más puntual en 1940:

Fue en Nieves — dijo mamá- allá en la hacienda de Urbina, entraron a balazos los villistas, Isidro estaba allí (el Kirilí), los sorprendieron. Ellos eran muy pocos y mataron a los más. A Urbina lo hirieron, luego se lo llevaron preso rumbo a Rosario, no llegaron; Urbina se perdió. La noche era tan oscura que parecía boca de lobo. Contaron que al general Villa le había sorprendido mucho la noticia de la muerte de su compadre Urbina, pero todos supieron que Fierro le dijo que Urbina se andaba volteando y que realmente él había tenido que intervenir a balazos. Mamá decía que todo se debió a una corazonada del Jefe de la División del Norte (Campobello, 1940: 84).

En 1940, Campobello suprimió de "Los heridos de Pancho Villa" un comentario sobre el asalto que cometió el coronel Rueda Quijano a su casa, así como una oración que mencionaba el manejo de armas de su mamá en el "El general Rueda" "Mamá sabía disparar todas las armas, muchas veces hizo huir hombres, hoy no podía hacer nada" [Campobello, 1931: 90]), quizás suavizando un poco el carácter agresivo de su madre; al mismo tiempo, dejó casi intacto el relato donde narra en detalle dicho asalto perpetrado por el coronel (en "El general Rueda"). Este ejemplo puede llevarnos a suponer que Campobello buscaba aminorar la representación de las contradicciones y los problemas internos del ejército villista, reordenando sus párrafos, sin negar los hechos.

Si se revisan los acontecimientos narrados en los relatos de Cartucho, se puede afirmar que todos se ubican en un margen temporal que va de 1911 a 1927, concentrándose, la mayoría, entre 1914 y 1916, lapso que coincide con la permanencia de Francisca y su familia en Parral durante el atrincheramiento de los villistas en la zona. Antes de la reconstrucción de la historia militar hecha por Salmerón, me fue prácticamente imposible dar con el nombre de ciertos personajes mencionados por Campobello, incluso en estudios clásicos sobre la Revolución, como los de Francisco Naranjo, Friedrich Katz o Alan Knight. Gracias a Salmerón, logré ubicar temporalmente algunos de los eventos narrados. Lo vivido por Francisca durante su adolescencia fue el repliegue y desmembramiento del ejército de Francisco Villa. El contacto que tuvo durante esos años con los soldados y sus historias no sólo se dio en la calle, sino también en el espacio íntimo. Muchos de los combatientes eran amigos, familiares (su propio hermano, apodado El Siete) o vecinos de los parralenses. En los relatos se puede percibir la cercanía que tanto Campobello como su familia tuvieron con la guerra.

La publicación de Cartucho en 1931 fue una afrenta para la facción vencedora de la Revolución; significó en la escritura de Campobello el inicio de una larga lucha a 


\section{Los [dos] cartuchos de Nellie Campobello}

favor del villismo. ¿Qué representó para Campobello ese momento histórico y político que decidió emprender una defensa pública de Villa? Después de que se imprimieran sus relatos revolucionarios, el 7 de diciembre de 1933 apareció el primer artículo en el que Campobello se declaró en permanente rechazo contra las versiones denostadoras del Centauro del Norte (Vargas y García, 2013: 305). Fue también, por ese entonces, cuando entró en contacto con Austreberta Rentería y dio inicio a las demandas públicas para exigir la protección, por parte del Estado, de la viuda del General y de sus hijos, pues vivían en condiciones sumamente precarias.

La escritura de Campobello varió según la fuerza de su compromiso con la historia, la verdadera historia. La ficción, la poética de las balas, se sometió a la verdad de los hechos, y de ello resultó que la voz de la niña se entreverara con una multiplicidad de voces de otros testigos, que Campobello consideró debían ser escuchados. Por eso, en 1940, aparece la voz popular del corrido. Las historias de los hombres del norte ya eran canciones. No importaba que el gobierno imprimiera libros y construyera monumentos para oficializar la Historia, los corridos los escribía y los cantaba el pueblo en la intimidad de su vida cotidiana. Esa fue la voz que Nellie Campobello supo recuperar en la segunda edición, para mostrar los créditos de su película, sus cuentos verdaderos.

\section{Bibliografía}

Ávila, Felipe y Pedro SALMERón

Historia breve de la Revolución Mexicana. México: Siglo XXI, 2017.

Campobello, Nellie [Francisca]

Francisca, 1o! México: Lidan, 1929.

Campobello, Nellie

Cartucho. Relatos de la lucha en el norte de México. México: Ediciones Intergrales, 1931.

Las manos de mamá. México: Juventudes de Izquierda, 1937.

Cartucho. Relatos de la lucha en el norte de México. México: EDIAPSA, 1940.

Mis libros. México: Compañía General de Ediciones, 1960.

Apuntes sobre la vida militar de Francisco Villa, en Obra reunida. México: Fondo de Cultura Económica, 2007.

Gallegos Téllez, José Roberto

"Correspondencia Martín Luis Guzmán-Nellie Campobello", en Revista de Literatura Mexicana Contemporánea, número 43, volumen 16 (octubre-diciembre 2009): 59-74. 


\section{| María José Ramírez}

Matamoro, Blas

"La verosimilitud: historia de un pacto", en Cuadernos Hispanoamericanos, número 444 (junio 1987), 83-101.

Matthews, Irene

Nellie Campobello. La centaura del Norte. México: Cal y Arena, 1997.

Rodríguez, Blanca

Nellie Campobello: eros y violencia. México: Universidad Nacional Autónoma de México, 1998.

SALMerón, Pedro

1915 México en guerra. México: Planeta, 2015.

VARGas VALDÉs, Jesús y Flor García Rufino

Nellie Campobello, Mujer de manos rojas. Prólogo de Jorge Aguilar Mora. México: Gobierno del Estado de Chihuahua, Secretaría de Educación, Cultura y Deporte, 2013. 